\title{
Stunting and Its Associated Factors among Early Adolescent School Girls of Gondar Town, Northwest Ethiopia: A School-Based Cross-Sectional Study
}

\author{
Azmera Tamrat, ${ }^{1}$ Yigizie Yeshaw $\mathbb{D}^{2,3}$ and Abel Fekadu Dadi ${ }^{3,4}$ \\ ${ }^{1}$ Gondar University Referral and Specialized Hospital, Gondar, Ethiopia \\ ${ }^{2}$ Department of Medical Physiology, School of Medicine, College of Medicine and Health Science, University of Gondar, \\ Gondar, Ethiopia \\ ${ }^{3}$ Department of Epidemiology and Biostatistics, Institute of Public Health, College of Medicine and Health Science, \\ University of Gondar, Gondar, Ethiopia \\ ${ }^{4}$ College of Medicine and Public Health, Flinders University, SA 5001, Australia
}

Correspondence should be addressed to Yigizie Yeshaw; yigizieyeshaw29@gmail.com

Received 26 August 2020; Revised 1 October 2020; Accepted 16 October 2020; Published 24 October 2020

Academic Editor: Mohammed F Faramawi

Copyright ( 2020 Azmera Tamrat et al. This is an open access article distributed under the Creative Commons Attribution License, which permits unrestricted use, distribution, and reproduction in any medium, provided the original work is properly cited.

\begin{abstract}
Introduction. Stunting is a crucial indicator of long-term chronic undernutrition that reflects a failure to reach a linear growth. Adolescent girls are potentially at a higher risk of stunting as they are traditionally married at an early age in low-income countries. In Ethiopia, stunting has mostly been examined in early childhood, with limited information at the early adolescent age. Therefore, this study is aimed at determining the prevalence of stunting and its associated factors among early adolescent school girls age 10 to 14 in Gondar town. Methods. We conducted a school-based cross-sectional study. A multistage sampling method was used to sample 662 adolescent girls in selected primary schools. A pretested, structured, and intervieweradministered questionnaire was used to collect the required data. Stata Version 14 and WHO Anthro-plus software were used to analyze the data. The bivariable and multivariable logistic regression model was fitted to identify factors associated with stunting. Adjusted Odds Ratio (AOR) with its 95\% confidence interval (CI) was calculated, and a $p$ value $\leq 0.05$ was considered to declare statistically significant variables. Results. The prevalence of stunting was $27.5 \%$ [95\% CI: $25.5 \%-29.5 \%$ ]. The odds of stunting were found to be higher among grade 5 students [AOR; 95\% CI: 1.90; 1.13-3.20], those who reported a daily meal frequency of less than three [AOR; 95\% CI: 2.37; 1.60-3.50], and those who were from food-insecure families [AOR; 95\% CI: 2.52 ; 1.70-3.73]. Adolescent girls whose mothers were government employees [AOR; 95\% CI: 0.48 ; $0.26-0.89$ ] or merchants [AOR; 95\% CI: $0.43 ; 0.28-0.67$ ] were less likely to be stunted compared to those whose mothers were housewives. Conclusion. Stunting among early adolescent girls is found to be a moderate public health problem. A school-based nutritional program might be helpful to reduce stunting in this group of adolescent girls.
\end{abstract}

\section{Introduction}

The United Nations (UN) defines early adolescence as those in the age category of $10-14$ years. $(1,2)$. Adolescence is a period of dramatic physical, cognitive, social, and emotional changes by which $15-20 \%$ of adult height is gained. The adolescent period requires adequate nutrition to maintain the development of optimal physical, cognitive, and linear growth $(3,4)$.
Stunting is a crucial indicator of long-term chronic undernutrition that reflects a failure to reach a linear growth due to prolonged food deprivation and illnesses during an early stage of life (5). Adolescent girls are potentially at a higher risk of stunting as they are traditionally married and being pregnant at an early age $(5,6)$. Stunting can result in reduced work capacity, weaker social skills, behavioral problems, and metabolic diseases during adulthood (7-9). More importantly, through fetal programming, stunted adolescent 
girls are more likely to give birth to underweight infants that would be stunted in later life $(6,10)$.

Based on previous studies, stunting among adolescent girls is $48 \%$ in Bangladesh and $47 \%$ in Nepal $(11,12)$. The two Indian studies reported a stunting prevalence of $46.6 \%$ (13) and $34.2 \%$ (11) in rural adolescent girls. In Ethiopia, the prevalence of stunting among adolescent girls ranges from $26.5 \%$ to $41.8 \%$ (14-16).

Different factors are associated with the stunting of early adolescent girls. Adolescents who came from a family size of greater than five, use unimproved sources of drinking water (17), have mothers with lower levels of educational attainment, and belong to food-insecure households (18) were more likely to be stunted. Being exposed to a contaminated environment and poor hygiene (19), skipping meals in the last two weeks, and having a poor dietary diversity score are also associated with an increased risk of stunting (20).

Although adolescent stunting was a common problem in Ethiopia, limited research has been published. Therefore, this study was conducted to assess the prevalence of stunting and its associated factors among the early adolescent school girls within an urban area of northwest Ethiopia.

\section{Methods and Materials}

2.1. Study Design, Setting, and Population. A school-based cross-sectional study was conducted to estimate the prevalence of stunting and its associated factors among early adolescent girls aged between 10 and 14 years and attending a government primary school in Gondar town. The data collection was conducted in January 2016. Gondar town is located in the Northwest region of Ethiopia, about $735 \mathrm{~km}$ from Addis Ababa, the capital city of Ethiopia. In the town, there are forty-three public primary schools and 16,331 students, of which 8,885 are early adolescent girls. All early adolescent girls present in selected governmental primary schools at the time of data collection were included. Those with a physical disability and critical illness were excluded.

2.2. Sample Size and Sampling Procedure. The sample size was calculated using a single population proportion formula by considering the following assumptions: stunting among adolescent girls in Debre Markos Town, Amhara region $(p=0.315)(17)$, a $5 \%$ margin of error, a 95\% confidence level, a nonresponse rate of $10 \%$, and a design effect of 2 . Accordingly, the final sample size was 731. In the first stage, 10 primary schools were selected from 43 primary schools using a lottery method (23\% of all primary schools). In the second stage, the total number of adolescent girls was proportionally allocated according to the size of the primary schools, and the final study participants were selected from each included primary school using a simple random sampling.

2.3. Variables of the Study. The dependent variable in this study was early adolescent stunting. Early adolescent stunting is defined by a height for age $Z$-score (HAZ) of less than minus two standard deviations ( $-2 \mathrm{SD})$ from the median value of the WHO reference standard. Participants with
HAZ scores of less than minus three standard deviations were severely stunted. The independent variables were education level of the student, educational status of the family, income, employment status, family size, information about food types such as teff (a type of crop used to make Enjera, a traditional food in Ethiopia), daily meal frequency, source of water, hand washing habits, and food security status. Food security was categorized as food secure for households with a raw score of $0-1$, and food insecure for households with a raw score of 2 and above (22). The Household Food Insecurity Access Scale was used to collect and categorize food security, and it has been validated in Ethiopia.

2.4. Data Collection Procedures and Quality. Data were collected from the students using a structured and intervieweradministered questionnaire. The questionnaire is prepared in English first and translated to Amharic and then retranslated to English to check for its consistency. The weight of adolescent girls was measured to the nearest $0.1 \mathrm{~kg}$ using a calibrated SECA weighing scale with light clothing and no shoes. The height of adolescent girls was also measured to the nearest $0.1 \mathrm{~cm}$ on a standing position without shoes using the same weighing device fitted with a sliding headpiece. Four diploma nurse data collectors and one Bachelor of Science nurse supervisor were recruited and trained for data collection. The questionnaire was pretested, and unclear questions were revised accordingly to maintain data quality. The weighing scale was zeroed before taking every other measurement. The collected data were reviewed and checked for completeness before data entry.

2.5. Data Processing and Analysis. After checking the collected data for completeness, it was entered into Epi-data version 3.1 and exported to Stata version 14.0 for analysis. The anthropometric measurement of height-for-age was calculated using the WHO Anthro-plus software. Bivariable and multivariable logistic regression analyses were performed to assess the association between different explanatory variables and early adolescent stunting. All variables with a $p$ value $<$ 0.2 in the bivariable analysis were entered into the multivariable logistic regression model. Odds ratio with its 95\% confidence intervals was estimated to identify factors associated with stunting. A $p$ value $\leq 0.05$ was considered to be statistically significant. Model fitness was checked using the Hosmer and Lemeshow goodness of fit test ( $p$ value $=0.99$ ).

2.6. Ethical Consideration. Ethical clearance of this study was granted by an Ethical Review Board of the University of Gondar. Permission was also obtained from the Gondar town Education Office and selected schools. Written consent from the guardians and assent from each study participant was taken before data collection. The information collected from this study remained confidential. Those who were severely stunted offered dietary counseling and linked to the nearest health institution for further management.

\section{Results}

3.1. Sociodemographic Characteristics of the Respondents. Six hundred and sixty-two (662) study participants were 
included in the study with a response rate of $90.56 \%$. The mean age and standard deviation $( \pm \mathrm{SD})$ of the study participants were $12.85( \pm 1.23)$ years. Most of $545(82.3 \%)$ study participants were Orthodox Christian. Among the respondents, $388(58.6 \%)$ had a family size of five and above. Four hundred and eighty-one (72.7\%) of the study participants had alive family (both the mother and father are alive), and $182(27.5 \%)$ of the study participants were grade seven (Table 1).

3.2. Nutrition and Health-Related Variables of the Respondents. From a total of 662 early adolescent school girls, $402(60.7 \%)$ of them had a daily meal frequency of three and above. Three hundred and twenty-two (48.6\%) of the study participants were identified as being food insecure. Regarding the availability of pure water, $34(5.1 \%)$ of the study participants used river water. One hundred and twenty-nine (19\%) of the participants reported an episode of diarrhea within the last two weeks. Four hundred and seventy-one (71.1\%) of participants had got information about food types from different sources (media, health professionals, and schools) (Table 2).

3.3. Prevalence and Associated Factors of Stunting. The overall prevalence of stunting in this study was $27.5 \%$ (95\% CI: $25.5 \%-29.5 \%)$. Of the total study participants, 60 (9.1\%) were found to be severely stunted. On bivariable logistic regression analysis, stunting was associated with the grade level of students, education level of their parents, employment status of their parents, whether their family is alive or not, the frequency of meals consumed per day, food security status, and with whom they are living with. However, after adjusting for other covariates, the grade level of students, the employment status of their mother, frequency of meals consumed per day, and food security status were significantly associated with stunting $(\boldsymbol{p} \leq \mathbf{0 . 0 5})$.

The odds of stunting among grade five students were 1.9 times higher than those among grade eight students [95\% CI: 1.13-3.20]. Students whose mothers were employed had a $57 \%$ reduced chance of being stunted than those whose mothers were housewives [AOR $=0.43$; 95\% CI: 0.28-0.67]. Students who had a merchant mother had a $52 \%$ reduced chance of being stunted compared with those whose mother was a housewife $[\mathrm{AOR}=0.48,95 \% \mathrm{CI}$ : 0.26-0.89]. The odds of stunting among students who had a meal frequency of less than three times per day were 2.37 times higher than those who had a meal frequency of three and above times per day [95\% CI: 1.60-3.50]. Students who were living in foodinsecure households had a 2.52 times higher chance of being stunted than those who were living in food-secure households [95\% CI: 1.70-3.73] (Table 3).

\section{Discussion}

This study tried to determine the prevalence of stunting and associated factors among early adolescent school girls. Grade level of students, employment status of their mother, frequency of meals consumed per day, and food
TABLE 1: Sociodemographic characteristics of early adolescent school girls, Gondar town, Northwest Ethiopia, 2016.

\begin{tabular}{|c|c|c|}
\hline Variable/category & Number & Percentage \\
\hline \multicolumn{3}{|l|}{ Age (in years) } \\
\hline 10 & 38 & 5.8 \\
\hline 11 & 73 & 11.0 \\
\hline 12 & 112 & 16.9 \\
\hline 13 & 166 & 25.1 \\
\hline 14 & 273 & 41.2 \\
\hline \multicolumn{3}{|l|}{ Religion } \\
\hline Orthodox & 545 & 82.3 \\
\hline Muslim & 69 & 10.4 \\
\hline Protestant & 45 & 6.8 \\
\hline Catholic & 3 & 0.5 \\
\hline \multicolumn{3}{|l|}{ Grade of students } \\
\hline Grade 5 & 178 & 26.9 \\
\hline Grade 6 & 173 & 26.1 \\
\hline Grade 7 & 182 & 27.5 \\
\hline Grade 8 & 129 & 19.5 \\
\hline \multicolumn{3}{|l|}{ Mother's education status } \\
\hline Illiterate & 148 & 22.3 \\
\hline Read \& write & 244 & 36.9 \\
\hline Diploma & 162 & 24.5 \\
\hline Degree and above & 108 & 16.3 \\
\hline \multicolumn{3}{|l|}{ Father's education status } \\
\hline Illiterate & 68 & 10.3 \\
\hline Read \& write & 221 & 33.4 \\
\hline Diploma & 175 & 26.4 \\
\hline Degree and above & 198 & 29.9 \\
\hline \multicolumn{3}{|l|}{ Father's occupation } \\
\hline Farmer & 89 & 13.4 \\
\hline Craftsman & 121 & 18.3 \\
\hline Merchant & 154 & 23.3 \\
\hline Government employee & 292 & 44.1 \\
\hline Daily laborer and private servant & 6 & 0.9 \\
\hline \multicolumn{3}{|l|}{ Mother's occupation } \\
\hline Housewife & 292 & 44.3 \\
\hline Government employee & 242 & 36.6 \\
\hline Merchant & 82 & 12.4 \\
\hline Daily laborer and private servant & 45 & 6.8 \\
\hline \multicolumn{3}{|l|}{ Alive parents } \\
\hline Both alive & 481 & 72.7 \\
\hline Mother alive & 104 & 15.7 \\
\hline Father alive & 44 & 6.6 \\
\hline Both dead & 33 & 5.0 \\
\hline \multicolumn{3}{|l|}{ Currently live with } \\
\hline Both parents & 384 & 58 \\
\hline One of their parents & 278 & 42 \\
\hline \multicolumn{3}{|l|}{ Family size } \\
\hline Less than five & 274 & 41.4 \\
\hline Five and above & 388 & 58.6 \\
\hline
\end{tabular}


TABLE 2: Nutrition and health-related characteristics of early adolescent school girls, Gondar town, North West Ethiopia, 2016.

\begin{tabular}{|c|c|c|}
\hline Variable/category & Number & Percentage \\
\hline \multicolumn{3}{|l|}{ Consume meat } \\
\hline Eat $<1$ per week & 458 & 69.2 \\
\hline Eat $\geq 1$ per week & 204 & 30.8 \\
\hline \multicolumn{3}{|l|}{ Consume milk } \\
\hline$<1$ in week & 529 & 79.9 \\
\hline$\geq 1$ a week & 133 & 20.1 \\
\hline \multicolumn{3}{|l|}{ Meal frequency } \\
\hline$<3$ meals/day & 260 & 39.3 \\
\hline$\geq 3$ meals/day & 402 & 60.7 \\
\hline \multicolumn{3}{|l|}{ Usual food type ingredient } \\
\hline Teff (Ethiopian staple food) & 563 & 85.0 \\
\hline Wheat & 51 & 7.7 \\
\hline Other (maize, rice, barley) & 48 & 7.3 \\
\hline \multicolumn{3}{|l|}{ HH food security status } \\
\hline Secure & 340 & 51.4 \\
\hline Insecure & 322 & 48.6 \\
\hline \multicolumn{3}{|l|}{ Water source } \\
\hline Pipe water & 628 & 94.9 \\
\hline River water & 34 & 5.1 \\
\hline \multicolumn{3}{|l|}{ Bed net use } \\
\hline Yes & 260 & 39.3 \\
\hline No & 402 & 60.7 \\
\hline \multicolumn{3}{|l|}{ History of diarrhea disease } \\
\hline Yes & 129 & 19.5 \\
\hline No & 533 & 80.5 \\
\hline \multicolumn{3}{|c|}{ Have information about food types } \\
\hline Yes & 471 & 71.1 \\
\hline No & 191 & 28.9 \\
\hline \multicolumn{3}{|l|}{ Hand wash after toilet } \\
\hline Yes & 601 & 90.8 \\
\hline No & 61 & 9.2 \\
\hline
\end{tabular}

security status were significantly associated with stunting among early adolescent school girls.

The prevalence of stunting in this study was $27.5 \%$, which is similar to a study conducted in Tigray (26.5\%) (15). This might be due to similarities in sociocultural conditions, feeding practices, economic growth, and level of awareness about the importance of proper nutrition during adolescents between the two regions of Ethiopia. However, it is higher than the one conducted in Addis Ababa (7.2\%) (21) and a report by the Ethiopian Health and Nutrition Research Institute (EHNRI) (23\%) (23). This difference could be related to variations in the level of awareness among Addis Ababa and Gondar town mothers. The importance of proper feeding practice and attention given for adolescent girls' nutrition by their families could be different in Addis Ababa than Gondar town. Moreover, economics influencing access to health care and availability of high quality foods generally play a key role in influencing differences between groups in the level of stunting. Furthermore, the difference in prevalence between our findings and the findings from EHNRI might be related to the size of the study. While our study was confined to a single town, the EHNRI study involved a nationally representative sample.

Our estimate was lower than an estimate reported by a study conducted in adolescent girls of Amhara region (31.5\%) (17), Bangladesh (49\%) (24), and India (50.3\%) (13) and early adolescent school girls of India (34.2\%) (14), Nepal (47\%), and Myanmar (39\%) (11). These variations might be explained by the differences in a study setting, economic status, sociocultural conditions, data collection instruments, and study populations.

The odds of stunting among grade five students were 2 times higher than those among grade eight students. This finding was consistent with a study conducted in Jimma zone (25). This might be due to the increased level of nutrition awareness of grade eight students than students in a lower grade. Participants who had a meal frequency of three and more times per day had reduced odds of stunting than those reporting a lower frequency, which is in line with a study conducted in the Oromia region (21). Adequate meal frequency indeed accelerates a linear growth of adolescents by sufficiently supplying essential nutrients for their body size. Adolescents who lived in food-insecure households had 2.5 times higher odds of being stunted than those who lived in food-secure households. This finding is in line with a study conducted in the Amhara region and Dale Woreda $(16,19)$. This could be true as food is very vital for the physical growth of adolescents in addition to its health benefits. Participants born from mothers who were government employees or merchants had a reduced chance of being stunted than those born from a housewife. Ethiopia is one of the patriarchal countries, and housewife mothers are waiting for the hand of their husbands to feed their kids as compared to those who independently fetch their income. Furthermore, housewife mothers are more likely to be uneducated and have low job access and decision-making power in the household, which would affect their knowledge about nutrition and the ability to earn a better income to care for their children (26).

As a limitation, there is a potential for recall bias, especially concerning food frequency questions. Another limitation of this study might be the social desirability bias. Moreover, since the study is a cross-sectional study, it also shares the limitations of cross-sectional study design, of which the issue of temporality is one. Hence, we are unable to show weather the outcome or some other independent variables come first. Therefore, the interpretation of these findings should consider these inherence limitations. However, our study clearly showed that adolescent nutritional interventions have been lagging in Ethiopia (27) though adolescent is the best window to intervene such nutritional problems (28). We hoped the recent National Nutrition (NNP) Program and the National School-based Nutrition Program (NSBNP) would bring a significant change in such burden of early adolescent stunting (29). 
TABLE 3: Bivariable and multivariable logistic regression analysis on factors associated with stunting among early adolescent school girls in Gondar town, Northwest Ethiopia, 2016.

\begin{tabular}{|c|c|c|c|c|}
\hline \multirow{2}{*}{ Variables } & \multicolumn{2}{|c|}{ Stunting } & \multicolumn{2}{|c|}{ Odds ratio } \\
\hline & Yes, $N(\%)$ & No, $N(\%)$ & COR $(95 \% \mathrm{CI})$ & $\operatorname{AOR}(95 \% \mathrm{CI})$ \\
\hline \multicolumn{5}{|l|}{ Educational status of mother } \\
\hline Illiterate & $51(35.4 \%)$ & $93(64.6 \%)$ & $2.40(1.31-4.40)$ & $0.59(0.35-1.01)$ \\
\hline Read \& write & $80(34.0 \%)$ & $155(66.0 \%)$ & $2.26(1.30-3.97)$ & $0.69(0.42-1.12)$ \\
\hline Diploma & $32(17.7 \%)$ & $149(82.3 \%)$ & $0.94(0.50-1.80)$ & $0.55(0.30-1.04)$ \\
\hline$\geq$ Degree & $19(18.6 \%)$ & $83(81.4 \%)$ & 1 & 1 \\
\hline \multicolumn{5}{|l|}{ Grade of students } \\
\hline Grade 5 & $65(36.5 \%)$ & $113(63.5 \%)$ & $1.80(1.25-2.61)$ & $1.90(1.13-3.20)^{*}$ \\
\hline Grade 6 & $37(21.4 \%)$ & $136(78.6 \%)$ & $0.65(0.43-0.97)$ & $1.32(0.72-2.44)$ \\
\hline Grade 7 & $54(29.7 \%)$ & $128(70.3 \%)$ & $0.61(0.38-0.98)$ & $1.27(0.68-2.56)$ \\
\hline Grade 8 & $26(20.2 \%)$ & $103(79.8 \%)$ & 1 & 1 \\
\hline \multicolumn{5}{|l|}{ Eating frequency/day } \\
\hline$<3$ per day & $111(42.7 \%)$ & $149(57.3 \%)$ & $3.47(2.43-4.95)$ & $2.37(1.60-3.50)^{*}$ \\
\hline$\geq 3$ per day & $71(17.7 \%)$ & $331(82.3 \%)$ & 1 & 1 \\
\hline \multicolumn{5}{|l|}{ Household food security } \\
\hline Food insecure & $129(40.1 \%)$ & $193(59.9 \%)$ & $3.62(2.51-5.23)$ & $2.52(1.70-3.73)^{*}$ \\
\hline Food secure & $53(15.6 \%)$ & $287(84.4 \%)$ & 1 & 1 \\
\hline \multicolumn{5}{|l|}{ Live with } \\
\hline Both mother \& father & $98(25.5 \%)$ & $286(74.5 \%)$ & 1 & 1 \\
\hline With father only & $46(29.1 \%)$ & $112(70.9 \%)$ & $1.15(0.57-2.20)$ & $0.88(0.37-2.11)$ \\
\hline With mother only & $13(27.7 \%)$ & $34(72.3 \%)$ & $0.90(0.79-1.81)$ & $1.10(0.60-1.84)$ \\
\hline Others $^{\mathrm{b}}$ & $25(34.2 \%)$ & $48(65.8 \%)$ & $1.52(0.89-2.59)$ & $1.20(0.63-2.27)$ \\
\hline \multicolumn{5}{|l|}{ Alive parents } \\
\hline Both mother \& father & $128(26.6 \%)$ & $353(73.4 \%)$ & 1 & 1 \\
\hline One of their parents alive & $54(29.8 \%)$ & $127(70.2 \%)$ & $1.20(0.80-1.71)$ & $0.91(0.58-1.40)$ \\
\hline \multicolumn{5}{|l|}{ Mother employment status } \\
\hline Housewife & $116(39.6 \%)$ & $177(60.4 \%)$ & 1 & 1 \\
\hline Government employee & $40(16.5 \%)$ & $202(83.5 \%)$ & $0.30(0.20-046)$ & $0.43(0.28-0.67)^{*}$ \\
\hline Merchant & $16(19.5 \%)$ & $66(80.5 \%)$ & $0.37(0.20-0.67)$ & $0.48\left(0.26-0.89^{*}\right.$ \\
\hline Other $^{\mathrm{a}}$ & $10(22.2 \%)$ & $35(77.8 \%)$ & $0.43(0.21-0.91)$ & $0.40(0.18-0.87)^{*}$ \\
\hline
\end{tabular}

${ }^{*}$ Statistical significant $(p$ value $<0.05) .{ }^{a}$ Daily laborer and private servants. ${ }^{\mathrm{b}}$ Sister, brother, aunt, and uncle.

\section{Conclusion}

The finding of this study demonstrated that stunting among early adolescent girls is a moderate public health problem. Being in a lower grade, having housewife mothers, daily meal frequency of less than three, and living in the food-insecure household increased the odds of being stunted. It is crucial to improve the food security status of households by increasing their income. It is also vital to increase nutrition awareness of the family and adolescent girls to improve their nutritional intake and tackle the intergenerational effect of adolescent malnutrition.

\section{Abbreviations}
AOR: $\quad$ Adjusted Odds Ratio
COR: Crud Odds Ratio
UN: $\quad$ United Nations

EHNRI: Ethiopian Health and Nutrition Research Institute NNP: National Nutrition Program

NSBNP: National School-based Nutrition Program

WHO: World Health Organization.

\section{Data Availability}

The data upon which the result was based could be accessed by a reasonable request made to the corresponding author.

\section{Conflicts of Interest}

The authors declare that they have no conflict of interest.

\section{Authors' Contributions}

AT collected the data, designed the study, performed the analysis, and interpreted the data. AFD and YY supervised 
the data collection, analysis, and interpretation of data. YY and AFD drafted the manuscript. All authors read and approved the final manuscript.

\section{Acknowledgments}

We would like to thank the Gondar City Education Bureau, respective school administrative bodies, data collectors, and study participants for their unreserved contribution to the success of this work. We are also very grateful for Mr. Heath Pillen for his extensive editing of this manuscript.

\section{References}

[1] Merriam Webster Dictionary, 2017, https://www.merriamwebster.com/dictionary/adolescence.

[2] M. Das Gupta, R. Engelman, J. Levy, L. Gretchen, T. Merrick, and J. E. Rosen, The Power of 1.8 Billion: Adolescents, Youth, and the Transformation of the Future, State of World Population, New York, USA, UNFPA, 2014.

[3] A. M. Prentice, L. M. Jarjou, S. E. Moore et al., "Reply to JL Leroy et. al," The American Journal of Clinical Nutrition, vol. 98, no. 3, pp. 856-857, 2013.

[4] WHO, Global nutrition targets 2025: stunting policy brief, 2014.

[5] R. E. Black, C. G. Victora, S. P. Walker et al., "Maternal and child undernutrition and overweight in low-income and middle-income countries," Lancet, vol. 6, pp. 15-39, 2013.

[6] A. M. Prentice, K. A. Ward, G. R. Goldberg et al., "Critical windows for nutritional interventions against stunting," The American Journal of Clinical Nutrition, vol. 97, no. 5, pp. 911-918, 2013.

[7] S. McGuire, "World Health Organization. Comprehensive Implementation Plan on Maternal, Infant, and Young Child Nutrition. Geneva, Switzerland, 2014," Advances in Nutrition, vol. 6, no. 1, pp. 134-135, 2015.

[8] N. Akseer, S. Al-Gashm, S. Mehta, A. Mokdad, and Z. A. Bhutta, "Global and regional trends in the nutritional status of young people: a critical and neglected age group," Annals of the New York Academy of Sciences., vol. 1393, no. 1, pp. 320, 2017.

[9] M. S. Rengma, K. Bose, and N. Mondal, "Socio-economic and demographic correlates of stunting among adolescents of Assam, North- east India," Anthropological Review, vol. 79, no. 4, pp. 409-425, 2016.

[10] E. J. Kwon and Y. J. Kim, "What is fetal programming? A lifetime health is under the control of in utero health," Obstet Gynecol Sci., vol. 60, no. 6, pp. 506-519, 2017.

[11] World Health Organization, Adolescent nutrition: a review of the situation in selected South-East Asian countries, Reg Off South-East Asia, New Delhi, 2006.

[12] G. Bishwajit, "Nutrition transition in South Asia: the emergence of non-communicable chronic diseases," F1000Research, vol. 4, no. 8, 2015.

[13] N. Mondal and J. Sen, "Prevalence of stunting and thinness among rural adolescents of Darjeeling district, West Bengal, India," Italian Journal of Public Health, vol. 7, no. 1, pp. 5461, 2010.

[14] D. De, K. Chatterjee, and K. Jana, "Prevalence of stunting and thinness among early adolescent school girls of Paschim Med- inipur district, West Bengal," International Journal Of Biological and Medical Research, vol. 2, no. 3, pp. 781-783, 2011.

[15] A. Mulugeta, F. Hagos, B. Stoecker et al., "Nutritional status of adolescent girls from rural communities of Tigray, Northern Ethiopia," Ethiopian Journal of Health Development, vol. 23, no. $1,2009$.

[16] M. M. Wassie, A. A. Gete, M. E. Yesuf, G. D. Alene, A. Belay, and T. Moges, "Predictors of nutritional status of Ethiopian adolescent girls: a community based cross sectional study," BMC Nutrition, vol. 1, no. 1, 2015.

[17] D. A. Zelellw, B. G. Gebreigziabher, K. A. Alene, B. A. Negatie, and T. A. Kasahune, "Prevalence and associated factors of stunting among schoolchildren," Debre Markos Town and Gozamen Woreda, East Gojjam Zone, Amhara Regional State, Ethiopia., vol. 2, 2013.

[18] H. Mekonnen, T. Tadesse, and T. Kisi, "Malnutrition and its correlates among rural primary school children of Fogera district, Northwest Ethiopia," Journal of Nutritional Disorders and Therapy S., vol. 12, p. 2161, 2013.

[19] M. Wolde, Y. Berhan, and A. Chala, "Determinants of underweight, stunting and wasting among schoolchildren," $B M C$ Public Health, vol. 15, no. 1, 2015.

[20] A. J. Prendergast, S. Rukobo, B. Chasekwa et al., "Stunting is characterized by chronic inflammation in zimbabwean infants," PLoS ONE, vol. 9, no. 2, p. e86928, 2014.

[21] A. Y. Mohammed, "Nutritional Status and Associated Risk Factors Among Adolescents Girls in Agarfa High School, Bale Zone, Oromia Region, South East Ethiopia," International Journal of Nutrition and Food Sciences, vol. 4, no. 4, p. 445, 2015.

[22] J. Coates, A. Swindale, and P. Bilinsky, "Household Food Insecurity Access Scale (HFIAS) for measurement of food access: indicator guide," Washington, DC: Food and Nutrition Technical Assistance Project, Academy for Educational Development., vol. 34, 2007.

[23] E. Health, "Nutrition Basline Surevy Report for the National Nutrition Program of Ethiopia, Nutrition Research," 2009, https://files.givewell.org/files/DWDA\%202009/GAIN/ nutrition_baseline_survey_report.pdf.

[24] J. H. Rah, P. Christian, A. A. Shamim, U. T. Arju, A. B. Labrique, and M. Rashid, "Predictors of stunting and thinness in post-menarcheal adolescent girls in rural Bangladesh," Public Health Nutrition, vol. 12, no. 12, pp. 2400-2409, 2009.

[25] H. Assefa, T. Belachew, and L. Negash, "Socio-demographic factors associated with underweight and stunting among adolescents in Ethiopia," The Pan African Medical Journal, vol. 20, 2015.

[26] International Food Policy Research Institute, Global Nutrition Report 2016: From Promise to Impact: Ending Malnutrition by 2030, Washington, DC, 2016.

[27] World Health Organization, "Nutrition in adolescence : issues and challenges for the health sector : issues in adolescent health and development," 2005, https://apps.who.int/iris/ handle/10665/43342.

[28] Z. A. Bhutta, J. K. Das, A. Rizvi et al., "Evidence-based interventions for improvement of maternal and child nutrition: what can be done and at what cost?," Lancet, vol. 382, no. 9890, pp. 452-477, 2013.

[29] Federal Democratic Republic of Ethiopia, National Nutrition Programme June 2013-June 2015, Government of Federal Democratic Republic of Ethiopia, Addis Ababa, 2013. 